\title{
Emerging Mental Health Diagnoses and School Disruption: An Examination Among Clinically Referred Children and Youth
}

\author{
Shannon L. Stewart, Janell A. Klassen, Chloe A. Hamza \\ Western University
}

\begin{abstract}
Previous research linking school disruption with mental health problems has largely relied on assessments of academic achievement to measure school disruption. Early disruptive classroom behaviour (e.g., conflict with school staff, negative attitudes toward school), however, may precipitate poor academic performance and may stem from emerging mental health concerns, particularly among young children. To address this gap in the literature, 912 clinically referred children and youth (ages 4-18 years old) were assessed using the interRAI Child and Youth Mental Health (ChYMH) assessment utilizing a cross-sectional study design. The ChYMH assessment evaluates school disruption independently of academic achievement, and includes a comprehensive assessment of the child's mental health functioning, needs, and preferences. A logistic regression analysis revealed that various provisional mental health diagnoses (i.e., attention-deficit/hyperactivity disorder, disruptive behaviour, mood disorders, and, to a lesser extent, anxiety) were associated with disruption in the classroom. Implications for school-based care planning are discussed.
\end{abstract}

One out of every five children within the school system suffers from a mental health issue (Bird, 1996; Kirby \& Keon, 2004; Offord, Boyle, Fleming, Blum, \& Grant, 1989). In Canada alone, an estimated 1.2 million children are currently suffering from significant mental health problems such as depression, anxiety, attentiondeficit/hyperactivity disorder, and other disorders (Kirby \& Keon, 2006). Although approximately $20 \%$ of school-aged children and youth are in need of mental health care services, research suggests that as many as $75 \%$ of these children and youth do not 
receive any treatment (Waddell, McEwan, Shepherd, Offord, \& Hua, 2005). Given that research has consistently shown that at least half of adult mental health problems have their onset in childhood (Kessler et al., 2005), it is crucial to provide early identification and treatment to children and youth, in an attempt to prevent life-course persistent and chronic mental health concerns.

A large body of literature has demonstrated a strong link between mental health concerns and school outcomes. More specifically, underachievement in the classroom is strongly associated with risk for a variety of mental health problems (Barrowman, Nutbeam, \& Tresidder, 2001; Breslau et al., 2009), including internalizing problems (e.g., anxiety and depression), externalizing difficulties (e.g., disruptive behaviour, conduct disorders, increased likelihood for criminal involvement) and substance use problems (Hemphala \& Hodgins, 2014; Henry, Knight, \& Thornberry, 2012; Lee, Cornell, Gregory, \& Fan, 2011; Liu, Chen, \& Lewis, 2011; Lochner \& Moretti, 2004; Quiroga, Janosz, Lyons, \& Morin, 2012; Strom \& Boster, 2007; Verweij, Huizink, Agrawal, Martin, \& Lynskey, 2013). Moreover, children who experience mental health concerns are at an increased risk for aversive long-term academic outcomes, including increased dropout rates in both elementary and secondary schools (Breslau, Lane, Sampson, \& Kessler, 2008), decreased likelihood of post-secondary enrolment (McLeod \& Kaiser, 2004), underemployment (Fergusson \& Woodward, 2002), decreased individual earnings (Oreopoulos, 2005), and greater reliance on social assistance (Christle, Jolivette, \& Nelson, 2007; Strom \& Boster, 2007). Together, this research provides compelling evidence that individuals who experience mental health concerns are less likely to realize the benefits of education across the lifespan.

Given the strong link between mental health and academic outcomes, the school setting provides an important initial opportunity for the identification of mental health problems among children and youth. In particular, early school disruption in the classroom may stem from emerging or existing mental health concerns among schoolaged children and youth. Despite advances in research on the association between mental health and school disruption, researchers have largely assessed school disruption using measures of academic achievement (e.g., academic performance, dropout rates). Although assessments of academic achievement are strongly associated with mental health, school disruptive behaviours in the classroom (e.g., conflict with school staff, negative attitudes toward school) may actually precede aversive academic outcomes (i.e., dropout, academic failures), and stem from emerging or existing mental health concerns.

\section{Current Study and Hypotheses}

Although the association between mental health problems and academic achievement has been widely documented, to our knowledge researchers have yet to examine associations among mental health issues and disruptive behaviours and attitudes within the classroom among school-aged children. The current study addresses this gap in the literature, by examining the association between early mental illness and school disruption (independent of academic achievement) among a clinically referred sample of school-aged children and youth. Critically, identifying children with emerging mental health concerns may serve to prevent poor long-term mental health and academic 
outcomes (e.g., school dropout, unemployment). In the present study we also incorporated a new and comprehensive assessment of children's mental health functioning, which could be integrated into school-based care planning for identifying high-risk children and youth in the classroom setting.

While several assessment tools assess the cognitive, emotional, and behavioural health and functioning of children and youth, scales designed to examine the likelihood of school disruption, when taken together as a component of a comprehensive assessment for examining the mental health of children and youth, are limited. Accordingly, this research utilizes the interRAI Child and Youth Mental Health (ChYMH; Stewart, Hirdes et al., 2015) assessment, a newly developed comprehensive assessment of individual needs and strengths, used across many child and youth mental health facilities in the Province of Ontario, Canada. Alternative school-based assessments of child functioning exist, but typically include a narrow range of symptoms and are insufficient for determining careplanning or treatment recommendations. In contrast, the interRAI Child and Youth suite of assessments provides a comprehensive assessment of child functioning and provides assessors with specific recommendations for care. The ChYMH assessment is preferable to simple combinations of multiple scales and measures, due to the inclusion of a variety of applications provided by interRAI assessments, including evidence-based care planning protocols, outcome measurement, resource allocation and utilization, and quality indicators. The ChYMH assessment is also preferable to other measures in that it is administered by trained clinicians and uses a multisource interview format (e.g., self-report, parents or primary caregivers, teachers, physicians), rather than a single assessor.

We hypothesized that individuals with a mental health diagnosis would be at an increased risk for experiencing school disruption. Due to gender socialization differences in externalizing behaviours and academic performance, which are evident between males and females throughout school-age years (Alatupa, Hintsanen, Mullola, \& Lipsanen, 2011; Legewie \& DiPrete, 2012; Maguire, Niens, McCann, \& Connolly, 2015; Wong et al., 2013), we predicted that males would be more likely than females to experience school disruption. Given the importance of early identification, this study will provide an important first examination of the association between early mental illness and disruption (independently of academic achievement) in the classroom.

\section{Methods}

\section{Participants}

The study sample consisted of 912 English-speaking children and youth $(68.3 \%$ male) aged 4-18 years $(\mathrm{M}=10.95, \mathrm{SD}=3.42)$ who accessed inpatient and outpatient community and hospital-based mental health services within the Province of Ontario from November 2012 to August 2015. Children and youth participating in this study were referred for mental health services for one or more of the following reasons: threat to self $(34.0 \%)$, threat to others $(43.3 \%)$, specific psychiatric symptoms $(72.0 \%)$, and/or involvement with the justice system (5.4\%). Additional participant demographic information is provided in Table 1. Children who presented with developmental or intellectual disability completed an alternative assessment at time of intake into care, and 
thus were not included in the present study. Participation in the study was voluntary and did not affect the health-care services provided to the child or youth, or to their families.

Table 1.

\section{Participant Demographics}

\begin{tabular}{lc}
\hline Demographic Variable & Descriptives \\
\hline Age & $M=10.95 ; S D=3.42$ \\
Sex-Male & $68.3 \%$ \\
Reasons for referral & \\
Threat to self & $34.0 \%$ \\
Threat to others & $43.3 \%$ \\
Specific psychiatric symptoms & $72.0 \%$ \\
Involvement with the justice system & $5.4 \%$ \\
Living arrangement prior to current contact with mental health agency & \\
With parent(s) or primary caregiver(s) & $90.7 \%$ \\
With foster family & $3.2 \%$ \\
Other (alone, siblings, other relatives, or non-relatives) & $6.1 \%$ \\
Time since last contact with community agency or health professional & \\
No contact in last year & $22.1 \%$ \\
31 days or more & $27.9 \%$ \\
30 Days or Less & $49.9 \%$ \\
Number of lifetime admissions & \\
None & \\
One to three & $75.8 \%$ \\
Four or more & $20.8 \%$ \\
\hline
\end{tabular}

\section{Measure: The interRAl ChYMH Assessment}

The ChYMH (Stewart, Hirdes et al., 2015) assessment builds a comprehensive picture of a child's medical, functional, psychological, social, and environmental strengths and needs as well as areas of risk, in order to inform care planning. Comprising approximately 400 clinical items, the $\mathrm{ChYMH}$ is based on a semi-structured interview format, and assesses a variety of domains including mental state indicators, substance use or excessive behaviour, strengths and resilience, cognition and executive functioning, independence of daily living, health conditions, family and social relations, stress and trauma, medication, prevention, service utilization, treatments, nutritional status, education, environmental assessment, and diagnostic and other health-related information. Numerous scales are embedded within the ChYMH that can be used for outcome measurement, and 30 Collaborative Action Plans (CAPs; Stewart, Theall et al., 2015) or evidence-informed care-planning protocols are utilized for identifying areas of imminent concern or risk.

Rigorous reliability and validity studies have been conducted across the family of interRAI assessments displaying strong psychometric properties for adults (Burrows, Morris, Simon, Hirdes, \& Phillips, 2000; Martin, Hirdes, Fries, \& Smith, 2007; Morris, 
Carpenter, Berg, \& Jones, 2000; Morris et al., 1997; Perlman \& Hirdes, 2008) as well as children and youth (Phillips et al., 2012; Phillips \& Hawes, 2015; Stewart, Baiden, \& Ninan, 2013; Stewart, Currie, Arbeau, Leschied, \& Kerry, 2015). In a forthcoming study, we also have found that the Risk for School Disruption (RSD) scale has strong interconsistency (.80), as well as strong inter-rater reliability (kappa $=.43$; Klassen, Hamza, Stewart, \& Marfil, 2016). In the present study, data collected on provisional DSM-IV diagnoses and risk for of school disruption were examined.

Provisional DSM-IV diagnoses. Clinicians reported whether a provisional or actual $D S M-I V$ diagnosis of attention-deficit/hyperactivity disorder, anxiety disorder, disruptive behaviour disorder, or mood disorder was indicated for each child or youth by a psychiatrist, psychologist, or attending physician at the time of the ChYMH assessment. The presence of a provisional $D S M-I V$ diagnosis was specified with a response of yes (1) or no (0).

The interRAI Risk for School Disruption (RSD) scale. The interRAI RSD scale is a 7-item scale that measures the risk for school disruption among children and youth in an attempt to identify those students at risk for school dropout. The presence (yes $=1$, no $=0$ ) of six school-related concerns were assessed (i.e., increased lateness or absenteeism, poor productivity at school, expressed intent to quit school, conflict with school staff, refusal to attend school, removal from school due to disruptive behaviour). One additional seventh item, "strong, persistent dissatisfaction with school," was scored based on the child and parent or primary caregivers' displeasure with school. This item was coded as $0=$ neither the child or parents/primary caregivers are dissatisfied with school, $1=$ either the child or parents/primary caregivers are dissatisfied with school independently, and 2 = both the child and the parents/primary caregivers are dissatisfied with school. Scores on the RSD scale ranged from 0 to 8 , with higher scores indicating increased risk for school disruption. We chose to categorize the dependent variable in the present study, because the RSD scale is ordinal (items do not equally contribute to total score), and because the RSD scale was skewed to the left (given violations to normality, using a categorical outcome can be preferable to a continuous outcome; Streiner, 2002). Further, it is also important to note that clinical cut-offs for the RSD scale are still in the process of being developed (Klassen et al., 2016). Thus, we decided to include any child above the median score on school disruption in our "disrupted" group. By using a lower threshold for school disruption, we can be more confident that our results are robust, even at low levels of school disruption.

\section{Procedure}

Data collection using the interRAI ChYMH assessment was approved by the University ethics board and carried out at 10 agencies providing inpatient and outpatient community and hospital-based mental health care services to children and youth within the Province of Ontario from November 2012 to August 2015. Clinicians obtained informed consent from participants' parents or primary caregivers as well as assent from the children and youth for completion of the ChYMH assessment as part of typical clinical practice. Although assessments could be completed by agencies for intake, milestone, or discharge evaluations, only the initial assessments at time of intake into treatment were used for this study. All clinicians involved in the study had a diploma or 
degree in the field of mental health (e.g., nurses, psychologists, psychiatrists, social workers, child and youth workers, speech and language pathologists) and 2 years of clinical experience working with children and youth. Additionally, clinicians received a 2-day training program on the administration of the ChYMH. Clinicians completed the assessment using multiple sources of information to evaluate mental health issues among children and youth. Direct contact with the family and their child or youth was often the first step; however, clinicians were encouraged to contact other service providers when possible in order to gain a comprehensive assessment of the child or youth (e.g., educators, physicians, child protective services). Although less than 5\% of data were missing, missing values were imputed using the expectation-maximum (EM) algorithm. EM is an iterative maximum-likelihood (ML) procedure in which a cycle of calculating means and covariances followed by data imputation is repeated until a stable set of estimated missing values is reached. Methodological research has demonstrated that ML estimation is preferable to pairwise deletion, listwise deletion, or means substitution (Schafer \& Graham, 2002).

\section{Data Analyses}

To address the link between mental health and the risk for school disruption using the ChYMH assessment, associations between provisional DSM-IV diagnoses and the RSD scale were assessed in the present study. First, frequency analyses were conducted for the mental health diagnoses, and then descriptives were reported for the school disruption scale. Next, the associations between the risk for school disruption and predictor variables (i.e., provisional or DSM-IV diagnosis of attentiondeficit/hyperactivity disorder, anxiety disorder, disruptive behaviour disorder, or mood disorder) were examined using a stepwise binary logistic regression analysis. All analyses were performed using SPSS version 18.0 software (SPSS Inc., Chicago, IL, USA).

\section{Results}

\section{Preliminary Analyses}

The most common provisional DSM-IV diagnosis among the 912 children and youth studied was attention-deficit/hyperactivity disorder (49.9\%), followed by anxiety disorder (32.1\%), disruptive behaviour disorder (25.8\%), and mood disorder (13.2\%). Among those with a provisional $D S M-I V$ diagnosis evaluated, $41 \%$ had only one diagnosis, $43 \%$ had two diagnoses, $13 \%$ had three diagnoses, and 3\% had all four diagnoses.

Chi-square tests of independence were conducted to examine the relation between having a provisional $D S M-I V$ diagnosis and the risk for school disruption. Attentiondeficit/hyperactive disorder and risk for school disruption were found to be significantly related, Pearson $\chi^{2}(1, \mathrm{~N}=912)=62.50, p=.000$, Cramer's $\mathrm{v}=.262$. Children with a provisional diagnosis of an attention-deficit/hyperactive disorder were at greater risk for school disruption than those without this diagnosis. Anxiety disorder and risk for school disruption were found to be significantly related, Pearson $\chi^{2}(1, \mathrm{~N}=912)=12.02, p=$ .001 , Cramer's $\mathrm{v}=.115$. Children with a provisional diagnosis of an anxiety disorder had a greater chance of being at risk for school disruption than those without a diagnosis of an 
anxiety disorder. Additionally, disruptive behaviour disorder and risk for school disruption were found to be significantly related, Pearson $\chi^{2}(1, \mathrm{~N}=912)=55.05, p=$ .000 , Cramer's v $=.246$. Children with a provisional diagnosis of a disruptive behaviour disorder were at greater risk for school disruption than those without a diagnosis of disruptive behaviour disorder. Finally, mood disorder and risk for school disruption were also found to be significantly related, Pearson $\chi^{2}(1, \mathrm{~N}=912)=10.23, p=.001$, Cramer's $\mathrm{v}=.106$. Children with a provisional diagnosis of a mood disorder were at greater risk for school disruption than those without this diagnosis. The observed frequencies are presented in Table 2.

Table 2.

Chi-Square Analyses

\begin{tabular}{lcc}
\hline \multirow{2}{*}{ Provisional DSM-IV Diagnosis } & \multicolumn{2}{c}{ Risk for School Disruption Observed } \\
\cline { 2 - 3 } & \multicolumn{2}{c}{ Diagnosis Present? } \\
& Yes & No \\
\hline Attention-deficit/hyperactivity disorders & $58.7 \%$ & $32.6 \%$ \\
\hline Anxiety disorders & $53.9 \%$ & $41.7 \%$ \\
Disruptive behaviour disorders & $66.4 \%$ & $38.4 \%$ \\
Mood disorders & $59.2 \%$ & $43.6 \%$ \\
\hline
\end{tabular}

\section{Primary Analysis}

A stepwise binary logistic regression analysis was used to predict the presence or absence of a high RSD score using the four provisional mental health diagnoses (i.e., attention-deficit/hyperactivity disorder, anxiety disorder, disruptive behaviour disorder, and mood disorder), while holding age and biological sex constant. The full model provided a significantly better fit to the data than the constant-only model, indicating that the predictors, when taken together, reliably distinguished between children who were at risk for school disruption and children who were not at risk for school disruption $\left(\chi^{2}=119.081\right.$, $d f=6, p<.000)$. A goodness-of-fit model was evidenced by non-statistically significant results on the Hosmer-Lemeshow test, $\chi^{2}(n=912)=8.160, d f=8, p=.418$. The full model correctly classified $67.4 \%$ of the cases. Results indicated that of the six predictors in the model, older age, male biological sex, and a mental health diagnosis of attention deficit hyperactivity disorder, disruptive behaviour disorder, and mood disorder significantly predicted risk for school disruption. A mental health diagnosis of an anxiety disorder was not significant in predicting risk for school disruption; however, there was a trend effect suggesting that those children and youth with anxiety disorders were at risk for school disruption. Children with a diagnosis of attention-deficit/hyperactivity disorder or disruptive behaviour disorder were 2 times more likely to be at risk for school disruption than children without these diagnoses. Similarly, children and youth with a diagnosis of mood disorder were at 1.68 times greater risk for school disruption than children without a diagnosis of 
mood disorder. Table 3 presents the results for the model including the regression coefficients, Wald statistics, odds ratios, and 95\% confidence intervals.

Table 3.

Regression Analysis

\begin{tabular}{lccccc}
\hline Predictor & $\boldsymbol{B}$ & $\begin{array}{c}\text { Wald } \\
\text { chi-square }\end{array}$ & $\begin{array}{c}\text { Odds ratio } \\
\text { Exp(B) }\end{array}$ & p value & $\begin{array}{c}\mathbf{9 5 \%} \\
\text { confidence } \\
\text { interval }\end{array}$ \\
\hline Age & 0.049 & 4.729 & 1.050 & 0.023 & {$[1.005,1.098]$} \\
$\begin{array}{l}\text { Biological sex-Male } \\
\text { Attention-deficit/ }\end{array}$ & -.634 & 15.756 & 0.530 & 0.000 & {$[0.388,0.725]$} \\
$\begin{array}{l}\text { hyperactivity disorders } \\
\text { Anxiety disorders }\end{array}$ & 0.706 & 21.093 & 2.027 & 0.000 & {$[1.499,2.740]$} \\
$\begin{array}{l}\text { Disruptive behaviour } \\
\text { disorders }\end{array}$ & 0.261 & 2.741 & 1.298 & 0.098 & {$[0.953,1.769]$} \\
Mood disorders & 0.762 & 19.048 & 2.142 & 0.000 & {$[1.521,3.016]$} \\
\hline
\end{tabular}

\section{Discussion}

Although mental health has been linked to poor academic outcomes and disrupted education, research regarding school disruption among children and youth lacks investigations made independently of academic performance. The present study addressed this gap in the literature by examining the association between provisional $D S M-I V$ diagnoses and the risk for school disruption (i.e., an assessment of the child's behaviours and attitudes associated with school). In addition, the results expand upon previous literature through the use of a new and comprehensive assessment tool for evaluating children's functioning and needs, providing a foundation for school-based care planning for high-risk children and youth. Consistent with our hypothesis, school disruption was found to be associated with poor mental health as indicated by the increased likelihood for the risk of school disruption when any of four provisional mental health diagnoses (attention-deficit/hyperactivity disorders, disruptive behaviour disorders, mood disorders, or anxiety disorders) were present. Moreover, as expected, males were more likely than females to be at risk for school disruption, potentially due to gender differences in behaviour, socialization, and academic performance. Further, results obtained from this study indicated that older children and youth were more likely than younger children and youth to be at risk for school disruption. Here we discuss potential explanations for the link between specific mental health diagnoses and suggest schoolbased care planning strategies.

Of the four provisional DSM-IV diagnoses examined in this study, attentiondeficit/hyperactivity disorder affected the greatest number of children and youth. Currently, there is an abundance of literature maintaining that children and youth who have attention-deficit/hyperactivity disorders tend to have poor academic outcomes (e.g., 
Barry, Lyman, \& Klinger, 2002; Birchwood \& Daley, 2012; Langberg et al., 2011; Loe \& Feldman, 2007; Martin, 2014). These findings are reflected in our study, which expands on the literature to suggest that children and youth who have a diagnosis of attentiondeficit/hyperactivity disorder are at an increased risk for school disruption, independent of academic achievement. For children and youth diagnosed with attentiondeficit/hyperactivity disorder and their non-attention-deficit/hyperactivity disorder peers, the degree to which the academic disparity is based on behavioural issues or on cognitive or neurological deficits is unclear. Even though many children and youth with a diagnosis of attention-deficit/hyperactivity disorder perform well below academic standards, as would be predicted given their cognitive abilities, those with more severe behavioural symptomology tend to have the poorest academic outcomes (Barry et al., 2002). Further research should be conducted to determine whether the severity of behavioural symptomology is associated with the risk for school disruption when academic achievement is not considered. It is likely that those children and youth who exhibit greater behavioural symptomology would be disengaged while in school, a confounding effect of the mental health diagnosis, leading to a greater risk for school disruption. Ultimately, the precipitating factor for school disruption among children and youth diagnosed with attention-deficit/hyperactivity disorder should be further investigated, as the current findings are not able to discern the direction of the relationship between a diagnosis of attention-deficit/hyperactivity disorder and risk for school disruption.

The three remaining provisional $D S M-I V$ diagnoses, disruptive behaviour disorders, (e.g., conduct disorder and oppositional defiant disorder), mood disorders, and anxiety disorders, are often comorbid with attention-deficit/hyperactivity disorder, but may also exist independently (Busch et al., 2002; Newcorn et al., 2001; Pliszka, 2000). Additionally, both externalizing problems, such as disruptive behaviour disorder, as well as internalizing problems, such as anxiety and depression, have been associated with an increased likelihood for school dropout (Hemphala \& Hodgins, 2014; Henry et al., 2012; Lee et al., 2011; Lochner \& Moretti, 2004). Our findings suggest that each of the stated $D S M-I V$ diagnoses (i.e., disruptive behaviours disorders, mood disorders, and anxiety disorders) also have a significant positive association with a risk for school disruption independently.

According to Tremblay (2010), disruptive behaviours are universal among children and as they age, these behaviours are expected to reduce in frequency as the child learns more socially appropriate behaviours. However, some children do not acquire appropriate behaviours, ultimately resulting in engagement in disruptive behaviours beyond the acceptable developmental timeframe. Since children spend most of their day at school, it is important that socially acceptable behaviours within the classroom are supported, modelling socially appropriate and non-disruptive behaviour that is expected across settings. Children who display disruptive behaviours may be able to be redirected if early intervention and treatment is provided through school-based care planning. Interestingly, children displaying aggression and conduct disorder symptoms often have comorbid psychiatric symptoms indicative of anxiety and depression. These children are at high risk for antisocial outcomes including criminal behaviour and poor psychosocial functioning, which could lead to premature educational cessation (Hemphala \& Hodgins, 2014; Serbin et al., 2010). 
Children as young as 5 or 6 years old are able to reliably express feelings of depression and should be identified early in an effort to intervene before the risk for school disruption increases significantly with age (Ialongo, Edelsohn, \& Kellam, 2001). It is possible that these feelings may be a precipitating factor influencing disengagement and therefore increasing the risk for school disruption. However, the child also may feel disengaged in school, leading to poor academic outcomes that maintain feelings of inadequacy, leading to depressive symptoms. The pattern of mental health and school disruption is not clear and requires further attention. Furthermore, although a little more than twice as many children and youth presented with a diagnosis of an anxiety disorder when compared to a mood disorder, a provisional diagnosis of an anxiety disorder was not directly predictive of an increased risk for school disruption. Nonetheless a trend was observed such that children and youth with a diagnosis of an anxiety disorder might be at greater risk for school disruption than those without any mental health diagnosis.

Low-level problem behaviours seem to be consistent throughout school-age years, including speaking out of turn, hindering others' attention, and disengagement; whereas serious problem behaviours such as destructiveness and aggression are relatively uncommon within the classroom (Sullivan, Johnson, Owens, \& Conway, 2014). The typical method for managing disruptive and disengaged problem behaviours, which may stem from emergent mental health concerns, is to punish the child based on a stepped approach (e.g., warning or reminder, in-class time out, out-of-class time out, referral to school leader, in-school suspension, out-of-school suspension, expulsion; Sullivan et al., 2014). Continuously reprimanding inappropriate behaviour exhibited by children and youth with demonstrated mental health issues by segregation from peers (or school removal all together) serves to increase the likelihood of poor school outcomes by actively disengaging the child in typical school programing. If a child is already disengaged from school, such as a child or youth with an emerging mental health concern, use of a stepped approach fails to address the underlying problem and actually discourages active engagement in education, which may further increase the likelihood for poor outcomes in adulthood.

Further, utilizing a stepped approach to punishment for classroom management locates the problem behaviour with the student rather than addressing the external environment of the classroom itself. In order to best serve children and youth, problem behaviours need to be addressed in the context of underlying mental health problems. Fortunately, with the introduction of new policies in the Province of Ontario, Canada, such as Supporting Minds (Ontario Ministry of Education, 2013), the stepped approach to student discipline is being replaced by a more appropriate model for interacting with children and youth with emergent mental health concerns. Positive behaviour intervention and support models emphasize using a positive, proactive, and systematic approach to dealing with students' problematic behaviour as guided by a clear set of expectations for all members of the school community (Kelm, McIntosh, \& Cooley, 2014). In these models, problematic behaviours are viewed as being reinforced by the environment; and therefore, a change in behaviour requires a change in the environment. This unique aspect removes the problem behaviour from the student, addressing the need for a change in the external environment of the classroom itself in order to support the child or youth in exhibiting appropriate behaviour. If a child is disengaged from school, 
such as a child or youth with an emerging mental health concern, using a positive behaviour support model to teach a small number of positively stated expectations that are applied across all areas of the school can address the underlying problem, independent of the child, and encourage active engagement in education (Kelm et al., 2014; McIntosh, Ty, \& Miller, 2014). Implementing evidence-informed classroom strategies that address the behaviour and emotional presentation in addition to supporting the student is of utmost importance to fostering school engagement (Kelm et al., 2014; Sullivan et al., 2014).

Several suggestions have been made for supporting disengaged children and youth and those with mental health concerns within the classroom. Although teachers may more readily detect externalizing behaviours, which are disruptive in nature, these should not be the focus of intervention when attempting to reduce the risk for school disruption (DuPaul et al., 2004). Teachers may be able to integrate and engage disengaged children and youth by modifying the physical environment of the classroom, adjusting curriculum, differentially allocating resources, revising their teaching style, or rotating activities within the classroom. Chiefly, behavioural interventions, modifications to instructions, and home-school communication programs (DuPaul, 2007) such as peer and parent tutoring, task or instructional modifications, classroom functional assessment procedures, self-monitoring, strategy training, and homework-focussed interventions should be implemented for children and youth exhibiting school disengagement or early warning signs of mental health (Daley \& Birchwood, 2010).

Further, teacher attitudes and beliefs within the classroom have the potential to decrease the gap in academic achievement and reduce the risk for school disruption among children with mental health concerns. DuPaul et al. (2004) found that among a sample of children with a diagnosis of attention-deficit/hyperactivity disorder and their non-attention-deficit/hyperactivity-disorder peers, teachers' perceptions of academic skills were the strongest predictors of academic achievement for all students. This is important when we consider how educators are trained because they directly affect their students through their attitudes and beliefs, as well as through the implementation of a variety of classroom strategies, to reduce the risk for school disruption. Despite the current emphasis on academics and classroom management, all teachers in training should also have basic training in mental health due to their crucial role in identifying the early warning signs of emergent mental health concerns (Climie, 2015; Whitley, Smith, \& Vaillancourt, 2013). Teacher training programs in Ontario, Canada, are beginning to incorporate coursework on understanding children's mental health (Climie, 2015), which is a major step toward improving mental health awareness and literacy among educators.

School-based care planning to help those children and youth at risk for school disruption does not only include educators. Parental involvement in education and positive familial beliefs about the value of education has been associated with reduced risk of school dropout (Jimerson, Egeland, Sroufe, \& Carlson, 2000). Specifically, youth who prematurely terminate their educational career were more likely to come from families who were of lower socioeconomic status (Ginsburg \& Bronstein, 1993) and less involved in their children's schooling (Yoshikawa, 1994). Specifically, school absenteeism has been associated with greater degrees of family dysfunction and poor emotional connections with family members (Kim \& Page, 2013). The achievement- 
related beliefs and behaviours of parents can have a profound influence on how children come to perceive their intellectual abilities and the value of learning and education (Eccles, Roeser, Vida, Fredricks, \& Wigfield, 2006). Given this connection, family support in relation to early education has been shown to have a protective factor for the prevention of later truancy, suggesting a cumulative protective model to circumvent early school departure (Yoshikawa, 1994).

\section{Limitations}

Although this research has several strengths, including a large sample size and the use of a comprehensive assessment tool that requires trained clinicians to collect information from multiple sources, the study is not without its limitations. First, it is important to consider the generalizability of the findings. Due to the fact that all of the children and youth assessed were accessing outpatient or inpatient community or hospital-based mental health services in the Province of Ontario, these findings are expected to be generalizable to clinically referred children and youth in provinces with similar demographic characteristics as Ontario across Canada. The findings, however, may not be generalizable to community-based samples of children and youth who have not been clinically referred for mental health services. Additionally, the classification for at-risk children and youth for school disruption was determined based on the median-split of the evaluated sample. Given that a clinical sample was assessed, it is possible that a community sample may have a different score that would be more indicative of a risk for school disruption. Finally, further testing of the psychometric properties of the RSD scale is needed with various sub-samples of children and youth; and longitudinal research is needed to examine the ability of the RSD scale to predict future school disengagement and dropout.

\section{Conclusions}

Early or emerging mental health illness may lead to increased school disruption, which if left unaddressed, may lead to school under-achievement and dropout. The results of the present study suggest that children and youth with a provisional or DSM-IV diagnosis of attention-deficit/hyperactivity disorder, anxiety disorder, disruptive behaviour disorder, or mood disorder are at greater risk for school disruption in the classroom than children and youth without a mental health diagnosis. Incorporating school-based planning and action plans for children with early or emerging mental health concerns, therefore, is important to circumvent potential long-term academic costs stemming from early classroom disruption.

\section{References}

Alatupa, S., Hintsanen, M., Mullola, S., \& Lipsanen, J. (2011). Childhood disruptive behaviour and school performance across comprehensive school: A prospective cohort study. Psychology, 2(6), 542-551.

Barrowman, C., Nutbeam, D., \& Tresidder, J. (2001). Health risks among early school leavers: Findings from an Australian study examining the reasons for, and consequences of, early school drop out. Health Education, 101(2), 74-82. 
Barry, T. D., Lyman, R. D., \& Klinger, L. G. (2002). Academic underachievement and attentiondeficit/hyperactivity disorder: The negative impact of symptom severity on school performance. Journal of School Psychology, 40(3), 259-283.

Birchwood, J., \& Daley, D. (2012). Brief report: The impact of attention deficit hyperactivity disorder (ADHD) symptoms on academic performance in an adolescent community sample. Journal of Adolescence, 35(1), 225-231.

Bird, H. R. (1996). Epidemiology of childhood disorders in a cross-cultural context. Journal of Child Psychology and Psychiatry, 37(1), 35-49.

Breslau, J., Lane, M., Sampson, N., \& Kessler, R. C. (2008). Mental disorders and subsequent educational attainment in a US national sample. Journal of Psychiatric Research, 42(9), 708-716.

Breslau, J., Miller, E., Breslau, N., Bohnert, K., Lucia, V., \& Schweitzer, J. (2009). The impact of early behavior disturbances on academic achievement in high school. Pediatrics, 123(6), $1472-1476$.

Burrows, A., Morris, J., Simon, S., Hirdes, J., \& Phillips, C. (2000). Development of a minimum data set-based depression rating scale for use in nursing homes. Age and Ageing, 29(1), 165-172.

Busch, B., Biederman, J., Cohen, L. G., Sayer, J. M., Monuteaux, M. C., Mick, E., Zallen, B., \& Faraone, S. V. (2002). Correlates of ADHD among children in pediatric and psychiatric clinics. Psychiatric Services, 53(9), 1103-1111.

Christle, C. A., Jolivette, K., \& Nelson, C. M. (2007). School characteristics related to high school dropout rates. Remedial and Special Education, 28(6), 325-339.

Climie, E. A. (2015). Canadian children's mental health: Building capacity in school-based intervention. Intervention in School and Clinic, 51(2), 122-125.

Daley, D., \& Birchwood, J. (2010). ADHD and academic performance: Why does ADHD impact on academic performance, and what can be done to support ADHD children in the classroom? Child: Care, Health and Development, 36(4), 455-464.

DuPaul, G. J. (2007). School-based interventions for students with attention deficit hyperactivity disorder: Current status and future directions. School Psychology Review, 36(2), 183-194.

DuPaul, G. J., Volpe, R. J., Jitendra, A. K., Lutz, J. G., Lorah, K. S., \& Gruber, R. (2004). Elementary school students with AD/HD: Predictors of academic achievement. Journal of School Psychology, 42(4), 285-301.

Eccles, J. S., Roeser, R., Vida, M., Fredricks, J., \& Wigfield, A. (2006). Motivational and achievement pathways through middle childhood. In L. Balter \& C. S. Tamis-LeMonda (Eds.), Child psychology: A handbook of contemporary issues (2nd ed., pp. 325-355). New York, NY: Psychology Press.

Fergusson, D. M., \& Woodward, L. J. (2002). Mental health, educational, and social role outcomes of adolescents with depression. Archives of General Psychiatry, 59(3), 225-231.

Ginsburg, G. S., \& Bronstein, P. (1993). Family factors related to children's intrinsic/extrinsic motivational orientation and academic performance. Child Development, 64(5), 1461-1474.

Hemphala, M., \& Hodgins, S. (2014). Do psychopathic traits assessed in mid-adolescence predict mental health, psychosocial, and antisocial, including criminal outcomes, over the subsequent 5 years? Canadian Journal of Psychiatry, 59(1), 40-49.

Henry, K. L., Knight, K. E., \& Thornberry, T. P. (2012). School disengagement as a predictor of dropout, delinquency, and problem substance use during adolescence and early adulthood. Journal of Youth and Adolescence, 41(2), 156-166. 
Ialongo, N. S., Edelsohn, G., \& Kellam, S. G. (2001). A further look at the prognostic power of young children's reports of depressed mood and feelings. Child Development, 72(3), 736-747.

Jimerson, S., Egeland, B., Sroufe, L. A., \& Carlson, B. (2000). A prospective longitudinal study of high school dropouts examining multiple predictors across development. Journal of School Psychology, 38(6), 525-549.

Kelm, J. L., McIntosh, K., \& Cooley, S. (2014). Effects of implementing school-wide positive behavioural interventions and supports on problem behaviour and academic achievement in a Canadian elementary school. Canadian Journal of School Psychology, 29(3), 195-212.

Kessler, R. C., Berglund, P., Demler, O., Jin, R., Merikangas, K. R., \& Walters, E. E. (2005). Lifetime prevalence and age-of-onset distributions of DSM-IV disorders in the National Comorbidity Survey Replication. Archives of General Psychiatry, 62(6), 593-602.

Kim, H.Y., \& Page, T. (2013). Emotional bonds with parents, emotional regulation, and school related behavior problems among elementary school truants. Journal of Child and Family Study, 22(1), 869-878.

Kirby, M., \& Keon, W. J. (2004). Mental health, mental illness, and addiction: Issues and options for Canada. Ottawa, ON: Senate of Canada, Standing Committee on Social Affairs, Science and Technology.

Kirby, M., \& Keon, W. J. (2006). Out of the shadows at last: Transforming mental health, mental illness, and addiction service in Canada. Ottawa, ON: Senate of Canada, Standing Committee on Social Affairs, Science and Technology.

Klassen, J. A., Hamza, C. A. Stewart, S. L., \& Marfil, P. V. (2016). The interRAI child and youth risk of school disruption scale (CY-RSD): Validation of a new scale to measure school disengagement and disruption among children and youth. Manuscript in preparation.

Langberg, J. M., Molina, B. S. G., Arnold, L.E., Epstein, J. N., Altaye, M., Hinshaw, S. P., ... Hechtman, L. (2011). Patterns and predictors of adolescent academic achievement and performance in a sample of children with attention deficit/hyperactivity disorder. Journal of Clinical Child \& Adolescent Psychology, 40(4), 519-531.

Legewie, J., \& DiPrete, T. A. (2012). School context and the gender gap in educational achievement. American Sociological Review, 77(3), 463-485.

Lee, T., Cornell, D., Gregory, A., \& Fan, X. (2011). High suspension schools and dropout rates for black and white students. Education and Treatment of Children, 34(2), 167-192.

Liu, J., Chen, X., \& Lewis, G. (2011). Childhood internalizing behaviour: Analysis and implications. Journal of Psychiatric and Mental Health Nursing, 18(1), 884-894.

Lochner, L., \& Moretti, E. (2004). The effect of education on crime: Evidence from prison inmates, arrests, and self-reports. American Economic Review, 94(1), 155-189.

Loe, I. M., \& Feldman, H. M. (2007). Academic and educational outcomes of children with ADHD. Journal of Pediatric Psychology, 32(6), 643-654.

Maguire, L. K., Niens, U., McCann, M., \& Connolly, P. (2015). Emotional development among early school-age children: Gender differences in the role of problem behaviours. Educational Psychology, 1-21.

Martin, A. J. (2014). The role of ADHD in academic adversity: Disentangling ADHD effects from other personal and contextual factors. School Psychology Quarterly, 29(4), 395-408.

Martin, L. R., Hirdes, J. P., Fries, B. E., \& Smith, T. F. (2007). Development and psychometric properties of an assessment for persons with intellectual disability: The interRAI ID. Journal of Policy and Practice in Intellectual Disabilities, 4(1), 23-29. 
McIntosh, K., Ty, S. V., \& Miller, L. D. (2014). Effects of school-wide positive behavioral interventions and supports on internalizing problems: Current evidence and future directions. Journal of Positive Behavior Interventions, 16(4), 209-218.

McLeod, J. D., \& Kaiser, K. (2004). Childhood emotional and behavioral problems and educational attainment. American Sociological Review, 69(5), 636-658.

Morris, J. N., Carpenter, I., Berg, K., \& Jones, R. N. (2000). Outcome measurement for use with home care clients. Canadian Journal of Aging, 19(S2), 87-105.

Morris, J. N., Fries, B. E., Steel, K., Ikegami, N., Bernabel, R., \& Carpenter, G. I. (1997). Comprehensive clinical assessment in community settings: Applicability of the MDSHC. Journal of the American Geriatrics Society, 45(1), 1017-1024.

Newcorn, J. H., Halperin, J. M., Jensen, P. S., Abikoff, H. B., Arnold, L. E., Cantwell, D. P., ... Vitiello, B. (2001). Symptom profiles in children with ADHD: Effects of comorbidity and gender. Journal of the American Academy of Child \& Adolescent Psychiatry, 40(2), 137-146.

Offord, D. R., Boyle, M. H., Fleming, J. E., Blum, H. M., \& Grant, N. I. (1989). Ontario child health study: Summary of selected results. Canadian Journal of Psychiatry, 34(1), 483-491.

Ontario Ministry of Education (2013). Supporting minds: An educator's guide to promoting students' mental health and well-being (Draft version). Retrieved from the Ontario Ministry of Education website at: http://www.edu.gov.on.ca/eng/document/reports/SupportingMinds.pdf

Oreopoulos, P. (2005). Canadian compulsory school laws and their impact on educational attainment and future earnings (Catalogue no. 11F0019, No. 251, Analytical studies branch research paper series). Ottawa, ON: Statistics Canada. Retrieved from Statistics Canada at http://publications.gc.ca/Collection/Statcan/11F0019MIE/11F0019MIE2005251.pdf

Perlman, C. M., \& Hirdes, J. P. (2008). The aggressive behavior scale: A new scale to measure aggression based on the minimum data set. Journal of the American Geriatrics Society, 56(12), 2298-2303.

Phillips, C. D., \& Hawes, C. (2015). The interRAI Pediatric Home Care (PEDS HC) assessment: Evaluating the long-term community-based service and support needs of children facing special healthcare challenges. Health Services Insights, 8(1), 17-24.

Phillips, C. D., Patnaik, A., Moudouni, D. K., Naiser, E., Dyer, J. A., Hawes, C., ... Elliott, T. R. (2012). Summarizing activity limitations in children with chronic illnesses living in the community: A measurement study of scales using supplemented interRAI items. BMC Health Services Research, 12(19), 1-10.

Pliszka, S. R. (2000). Patterns of psychiatric comorbidity with attention-deficit/hyperactivity disorder. Child and Adolescent Psychiatric Clinics of North America, 9(3), 525-540.

Quiroga, C. V., Janosz, M., Lyons, J. S., \& Morin, A. J. (2012). Grade retention and seventh-grade depression symptoms in the course of school dropout among high-risk adolescents. Psychology, 3(9), 749-755.

Schafer, J. L., \& Graham, J. W. (2002). Missing data: Our view of the state of the art. Psychological Methods, 7(1), 147-177.

Serbin, L. A., Temcheff, C. E., Cooperman, J. M., Stack, D. M., Ledingham, J., \& Schwartzman, A. E. (2010). Predicting family poverty and other disadvantaged conditions for child rearing from childhood aggression and social withdrawal: A 30-year longitudinal study. International Journal of Behavioural Development, 35(2), 97-106.

Stewart, S. L., Baiden, P., \& Ninan, A. (2013, November). The aggressive behavior scale and predicting control interventions among youth. Poster presented at the 33rd Annual Meeting of 
the Canadian Academy of Child and Adolescent Psychiatry (CACAP). Vancouver Wall Centre Hotel, November 17th-19th, 2013. Vancouver, BC, Canada.

Stewart, S. L., Currie, M., Arbeau, K., Leschied, A., \& Kerry, A. (2015). Assessment and planning for community and custodial services: The application of interRAI assessment in the youth justice system. In R. Corrado, A. Leschied, P. Lussier, \& J. Whatley (Eds.), Serious and violent young offenders and youth criminal justice: A Canadian perspective (pp. 355-397). Burnaby, BC: Simon Fraser University.

Stewart S. L., Hirdes, J. P., Curtin-Telegdi, N., Perlman, C., MacLeod, K., Ninan, A., ... Topinková, E. (2015). interRAI Child and Youth Mental Health (ChYMH) assessment form and user's manual (Version 1). Washington, DC: interRAI.

Stewart, S. L., Theall, L. A., Morris, J. N., Berg, K., Björkgren, M., Declercq, A., ... Topinková, E. (2015). interRAI Child and Youth Mental Health Collaborative Action Plans (CAPs) for use with the interRAI Child and Youth Mental Health (ChYMH) assessment instrument (Research version 1, standard edition). Washington, DC: interRAI.

Streiner, D. L. (2002). Breaking up is hard to do: The heartbreak of dichotomizing continuous data. Canadian Journal of Psychiatry, 47(1), 262-266.

Strom, R. E., \& Boster, F. J. (2007). Dropping out of high school: A meta-analysis assessing the effect of messages in the home and in school. Communication Education, 56(4), 433-452.

Sullivan, A. M., Johnson, B., Owens, L., \& Conway, R. (2014). Punish them or engage them? Teachers' views of unproductive student behaviours in the classroom. Australian Journal of Teacher Education, 39(6), 43-56.

Tremblay, R. E. (2010). Developmental origins of disruptive behaviour problems: The 'original sin' hypothesis, epigenetics and their consequences for prevention. Journal of Child Psychology and Psychiatry, 51(4), 341-367.

Verweij, K. J. H., Huizink, A. C., Agrawal, A. C., Martin, N. G., \& Lynskey, M. T. (2013). Is the relationship between early-onset cannabis use and educational attainment causal or due to common liability? Drug and Alcohol Dependence, 133(1), 580-586.

Waddell, C., McEwan, K., Shepherd, C. A., Offord, D. R., \& Hua, J. M. (2005). A public health strategy to improve the mental health of Canadian children. Canadian Journal of Psychiatry, $50(1), 226-233$.

Whitley, J., Smith, J. D., \& Vaillancourt, T. (2013). Promoting mental health literacy among educators: Critical in school-based prevention and intervention. Canadian Journal of School Psychology, 28(1), 1156-1170.

Wong, T. M., Loeber, R., Slotboom, A. M., Bijleveld, C. C., Hipwell, A. E., Stepp, S. D., \& Koot, H. M. (2013). Sex and age differences in the risk threshold for delinquency. Journal of Abnormal Child Psychology, 41(4), 641-652.

Yoshikawa, H. (1994). Prevention as cumulative protection: Effects of early family support and education on chronic delinquency and its risks. Psychological Bulletin, 115(1), 28-54.

\section{Authors' Note}

Correspondence concerning this article should be addressed to Shannon L. Stewart, Applied Psychology, Faculty of Education, Western University, 1137 Western Road, London, ON, N6G 1G7, Canada. Email: sstewa24@uwo.ca 